\title{
A FINE-GRAINED ANALYSIS OF A MONK PARAKEET (MYIOPSITTA MONACHUS) NEST SUGGESTS A NONHOMOGENEOUS INTERNAL STRUCTURE
}

\section{RAPID COMMUNICATION}

\author{
Corrado Battistia,b* Giuliano Fanellic
}

\author{
aTorre Flavia' LTER (Long Term Ecological Research) Station, Protected Areas - Regional Park Service, Città Metropolitana di \\ Roma Capitale, viale G. Ribotta, 41, 00144 Rome, Italy \\ ${ }^{b}$ Faculty of Science - University of Rome III, viale G. Marconi, 446, 00146 Rome, Italy \\ ORCID: http://orcid.org/0000-0002-2621-3659 \\ c Dipartimento di Biologia, Seconda Università di Roma Tor Vergata, Via della Ricerca Scientifica, 00133 Rome, Italy \\ *Corresponding author. Email: c.battisti@cittametropolitanaroma.gov.it
}

\begin{abstract}
Article history
Received: 1 October 2020

accepted: 29 March 2021
\end{abstract}

\section{Keywords:}

Nest sectors; branch diameter; branch length; structural diversity; thermoregulation

\begin{abstract}
We report first data on the fine-grained structure (branch diameter, length and diversity) in three different sectors [core (central side), buffer (peripheral side), and nest chamber)] of a nest of Monk Parakeets (Myiopsitta monachus) from a non-native breeding site located in an urban park (Rome, central Italy). The central core sector was characterized by longer and thicker branches capable of supporting the nest. The peripheral part (buffer) was characterized by less long and less thick branches with the function of completing the structure. Branches building the nest chamber were shorter and less thick but very diversified in size, because they included both small branches supplied inside the chamber and longer branches covering it. This diversification of the internal chamber (nest chamber) could be functional to maintain stable temperatures of incubator chambers compared to large fluctuations outside the nest. The presence of leaves of herbaceous species (Hordeum leporinum) could play a bactericidal role for the nest plant material.
\end{abstract}

\section{INTRODUCTION}

Unique among parrots, Monk Parakeets (Myiopsitta monachus) build communal nest structures (used yearround) that contain several compartments (nest chambers; Navarro et al. 1992), each with a separate entrance and belonging to an individual pair (Caccamise and Weathers 1977; Eberhard 1996; Burger and Gochfeld 2005; Romero et al. 2015). However, although studies focused on nest-tree selection in Monk Parakeets are largely available both in the species native range and in areas of recent introduction (Hyman and Pruett-Jones 1995; Burger and Gochfeld 2000; Pranty 2009; Volpe and Aramburú 2011; Avery et al. 2012; Burgio et al. 2014; Reed et al. 2014; Romero et al. 2015; Di Santo et al. 2017), data on nest architecture are still relatively scanty (see Harrison 1973).

In this note, we examine the fine-grained structure of a nest of Monk Parakeets, reporting data on plant species used and on the size (length and diameter) and diversity of branches in three different nest sectors.

\section{METHODS}

We obtained data from a nest fallen on the ground inside a small historical urban park (Villa Sciarra, Rome, central Italy; geographical coordinates: $41^{\circ} 53^{\prime} 04.1^{\prime \prime} \mathrm{N}$ $12^{\circ} 27^{\prime} 49.2^{\prime \prime} \mathrm{E} ; 70 \mathrm{~m}$ a.s.1.; 7 hectares in size). In this park, a small population of non-native Monk Parakeet occurs and a large number of native and allochthonous/ ornamental trees are present (Cedrus libani, Cupressus sempervirens, Quercus ilex, Ligustrum sp., Gingko biloba, Laurus nobilis, Phoenix canariensis, Celtis australis, Tilia americana, Ulmus sp. Cycas sp.; Catalano 1995).

The nest $(100 \mathrm{~cm}$ in length, $50 \mathrm{~cm}$ in height, $80 \mathrm{~cm}$ in width) had at least two chambers and was built of branches belonging to different tree species (mainly Tilia americana and Celtis australis). In the nest chambers, leaves of Hordeum leporinum were present.

To characterize nest structure, we hypothesized that it could have been built using branches of different sizes according to three sectors (distinguished with respect to an internal-external gradient and a macroscopic structural gradient; see also Eberhard 1998): an internal sector (nest chamber, internal to nest), a central structure (core; immediately surrounding the chamber), and a peripheral sector (buffer; surrounding the core sector on the exterior).

We took a sample of branches from each of the three sectors. For each branch, the following measures were taken using a professional calliper (Vernier LS PRO): 
length (in $\mathrm{cm}$ ), diameter (in $\mathrm{mm}$ ), and length/diameter ratio, obtaining the average values (and standard deviation) for each sector. Since data were not normally distributed ( $p>0.01$; one-sample Kolmogorov-Smirnov test), the averages were compared between sectors using the Kruskal Wallis test (n-unpaired data), and the paired data were computed using the U Mann-Whitney test (Dytham 2011). The frequency distribution of the length and diameter size classes for the three sectors was calculated and compared using the Kolmogorov-Smirnov test. We used the SPSS 13.0 software for statistical analyses. From the frequency values, a structural diversity index was calculated by applying the Shannon-Wiener index $\left(H^{\prime}=\mathrm{fr}_{\mathrm{i}} \operatorname{lnfr}_{\mathrm{i}}\right.$, where $\mathrm{fr}_{\mathrm{i}}$ is the relative frequency of size categories), obtaining a diversity value of diameters $\left(\mathrm{H}^{\prime}{ }_{\text {diam }}\right)$ and lengths $\left(\mathrm{H}_{\text {length }}\right)$ for the three sectors.

\section{RESULTS AND DISCUSSION}

In total, we measured 437 branches (core: 152, buffer: 180; nest chamber: 105). The lengths of the branches were significantly different between the three sectors (Kruskall-Wallis test; Table 1), with the core sector having significantly longer branches compared to the buffer sector $(\mathrm{Z}=-2.445, p<0.05$; Mann Whitney $\mathrm{U}$ test) and to the nest chamber $(Z=-6.776, p<0.001$, Mann Whitney $U$ test). The branches of the nest chamber were shorter in length than the branches of the buffer $(\mathrm{Z}=-5.887, p<0.001$, Mann Whitney $\mathrm{U}$ test $)$.

Differences in branch diameter among the three sectors were significant (Kruskal-Wallis test; Table 1). Branch diameter in the core sector was significantly larger compared to nest chamber and buffer sectors (core-nest: $Z=-4.254$, core-buffer: $Z=-5.73, p<0.01$ ). However, there was no significant difference between nest and buffer sectors $(\mathrm{Z}=-0.472, p=0.636$; Mann Whitney U test).

There was a significant difference in the length/diameter ratio between different sectors (Kruskal Wallis test; Table 1). The branches were longer and thinner in the buff- er, with a significantly higher average length/diameter ratio compared to the core and the nest chamber sector (respectively, $Z=-3.771$ and $Z=-6.511$, both of them: $p<0.001$ ), with the nest chamber sector having the lowest average ratio (i.e. shorter and thicker branches: $\mathrm{Z}=$ -4.068, $p<0.001$; Mann Whitney U test).

The frequency distributions of branch lengths and diameters were significantly different between sectors (core, nest chamber and buffer: respectively, $\mathrm{D}=1.45$, $p=0.038$ and $\mathrm{D}=2.67$, both of them: $p<0.001$; Kolmogorov Smirnov test). Considering branch lengths, the most represented category was $>30-40 \mathrm{~cm}$ in the core vs. $>20-30 \mathrm{~cm}$ both in the nest chamber and in the buffer (Figure 1), while considering branch diameters, the most represented category was $>4-5 \mathrm{~mm}$ in the core compared to $>2-3 \mathrm{~mm}$ in the nest chamber and buffer sectors (Figure 2).

The branches in the nest chamber showed the highest heterogeneity in both lengths $\left(\mathrm{H}^{\prime}{ }_{\text {length }}=1.581\right.$ vs 1.268 of the core sector and 1.241 in the buffer) and diameters

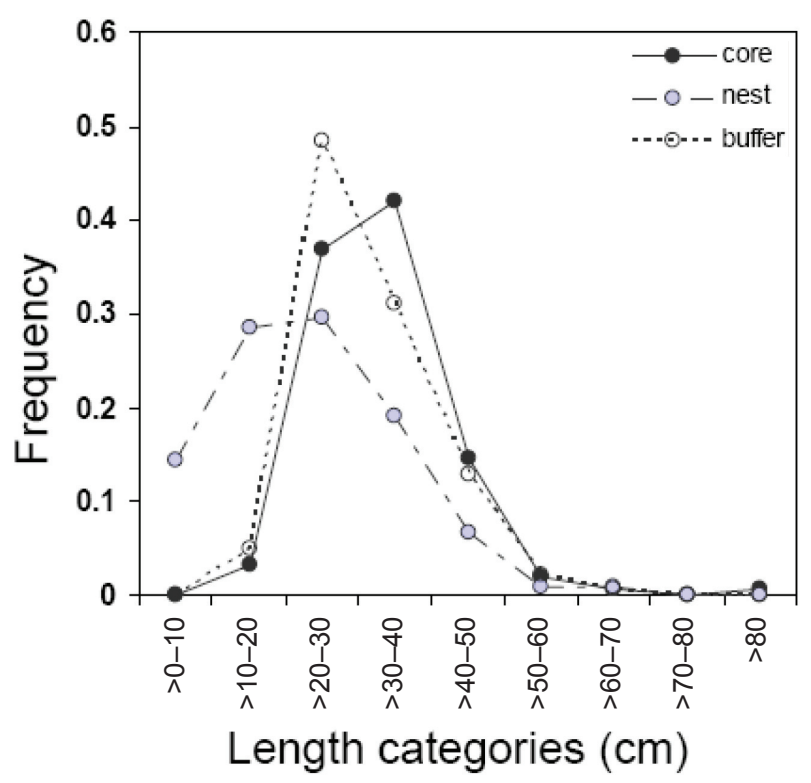

Figure 1. Frequency distribution of length categories for three different sectors (core, nest chamber and buffer) of a Myiopsitta monachus nest.

Table 1. Mean values (and \pm standard deviation) of branch length (in $\mathrm{cm}$ ), diameter (in $\mathrm{mm}$ ) and diameter/length ratio for three different sectors of a Myiopstta monachus nest. Number of branches (N), size range (min-max) and Kruskal-Wallis test $(\mathrm{K}-\mathrm{W})$ values are reported. $* *=p<0.001$.

\begin{tabular}{|l|c|c|c|c|}
\hline \multirow{2}{*}{} & \multicolumn{3}{|c|}{ Sectors } & K-W \\
\cline { 2 - 4 } & Core & Nest chamber & Buffer & Chi \\
\hline Length $(\mathrm{cm})$ & $32.66( \pm 9)$ & $23.02( \pm 12.14)$ & $30.67( \pm 8.55)$ & $53.96^{* *}$ \\
\hline Range & $13.5-82.1$ & $3.9-61.9$ & $12.3-64$ & $35.72^{* *}$ \\
\hline Diameter $(\mathrm{mm})$ & $3.65( \pm 1.02)$ & $3.08( \pm 1.27)$ & $3.02( \pm 1.16)$ & \\
\hline Range & $1.5-6$ & $0.5-7$ & $1-7$ & $47.98^{* *}$ \\
\hline Diameter/length ratio & $9.52( \pm 3.25)$ & $7.98( \pm 4.19)$ & $11.24( \pm 4.52)$ & \\
\hline Range & $3.42-21.55$ & $1.56-24.33$ & $4.1-34.6$ & 180 \\
\hline $\mathrm{N}$ & 152 & 105 & & \\
\hline
\end{tabular}




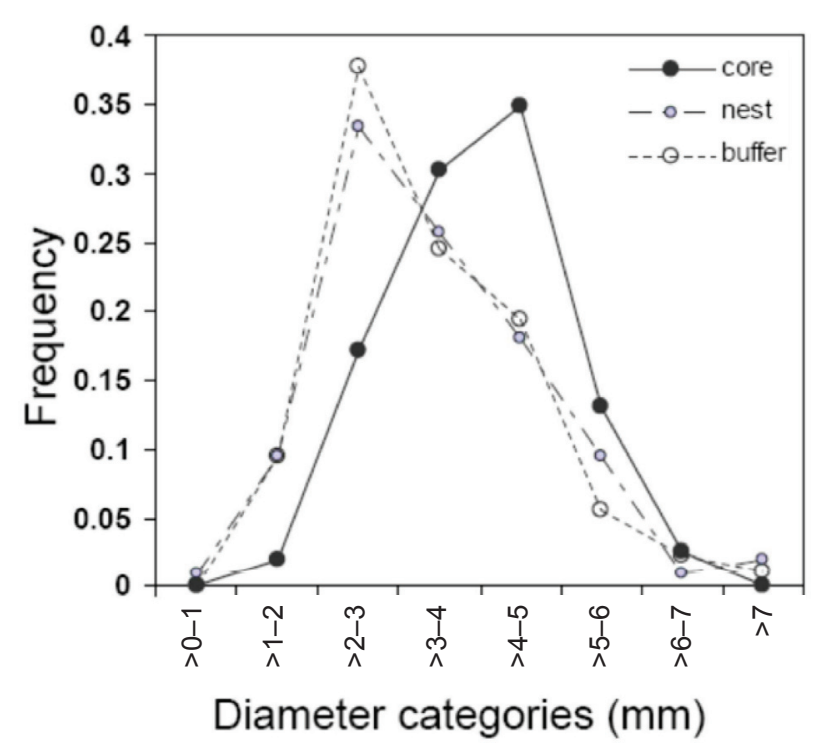

Figure 2. Frequency distribution of diameter categories for three different sectors (core, nest chamber and buffer) of a Myiopsitta monachus nest.

$\left(\mathrm{H}_{\text {diam }}^{\prime}=1.637\right.$ vs. $1.471 \mathrm{in}$ the core sector and $1.549 \mathrm{in}$ the buffer).

Overall, our data suggested that the fine-grained internal branch structure of the studied Monk Parakeet nest could be nonhomogeneous. The central core sector was characterized by longer and thicker branches, probably more able to support the stability of the nest structure. The peripheral part (buffer) was characterized by less long and less thick branches with the function of completing the structure. Branches building the nest chamber were the shortest and the thinnest but very diversified in size, because they included both small branches supplied inside the chamber and longer branches covering it. This diversification, together with the presence of leaves of herbaceous species (yet reported from Aramburú et al. 2002), suggested a role in maintaining stable internal temperatures with respect to the larger thermal fluctuations outside the nest (see Viana et al. 2016). Moreover, these authors observed that some plants brought to the nest inhibited the growth of pathogenic bacteria (bactericidal role of nest plant material), therefore increasing reproductive rates (Viana et al. 2016; see also RuizCastellano et al. 2016). Although a wide literature is available regarding the role of nest structure in maintaining an internal stable microclimate (e.g. Bartholomew et al. 1976, Sonnenberg et al. 2020), a specific role of branches is still poorly reported (e.g. for Monk Parakeets: Caccamise and Weathers 1977). However, it has been observed that nest branch size and bird body mass are directly correlated in birds (see Deeming 2018), and a high frequency of these materials could reflect a relatively large body mass of this species. Leaf presence in nests may also create an appropriate microclimate for both parents and offspring (Mainwaring et al. 2014). For large species, leaves have been suggested to function as an insect repellent (McDonald et al. 1995).

Although we analyzed a representatively large number of branches in this note, we obtained the first data only from a focal nest. Therefore, further research from a larger sample size is necessary to confirm these preliminary data, also searching for further structural differences in the colonial nests of this species.

\section{ACKNOWLEDGMENTS}

An anonymous reviewer and Editor-in-Chief (Denis Copilaş-Ciocianu) provided useful comments and suggestions which improved the first draft of the manuscript.

\section{COMPETING INTEREST}

The authors declare that they have no competing interest.

\section{DISCLOSURE STATEMENT}

No potential conflict of interest was reported by the authors.

\section{REFERENCES}

Aramburú, R., A. Cicchino, and E. Bucher. 2002. Material vegetal fresco en cámaras de cría de la cotorra argentina Myiopsitta monachus (Psittacidae) [Green plant material in breeding chambers of the Monk Parakeet Myiopsitta monachus (Psittacidae)]. Ornitología Neotropical 13: 433-436.

Avery, M. L., E. A. Tillman, K. L. Keacher, J. E. Arnett, and K. J. Lundy. 2012. Biology of Invasive Monk parakeets in South Florida. The Wilson Journal of Ornithology 124: 581-588.

Bartholomew G. A., F. N. White, and T. R. Howell. 1976. The thermal significance of the nest of the sociable weaver Philetairus socius: summer observations. Ibis 118: 402-411.

Burger, J., and M. Gochfeld. 2000. Nest site selection in Monk parakeets (Myiopsitta monachus) in Florida. Bird Behavior 13: 99-105.

Burger, J., and M. Gochfeld. 2005. Nesting behavior and nest site selection in Monk parakeets (Myiopsitta monachus) in the Pantanal of Brazil. Acta Ethologica 8: 23-34. 
Burgio, K. R., M. A. Rubega, and D. Sustaita. 2014. Nestbuilding behavior of Monk parakeets and insights into potential mechanisms for reducing damage to utility poles. PeerJ 2: e601.

Caccamise, D. F., and W. W. Weathers. 1977. Winter nest microclimate of Monk parakeets. The Wilson Bulletin 89: 346-349.

Catalano, M. 1995. Ville, parchi e verde pubblico. L'Ecosistema Roma: ambiente e territorio, conoscenze attuali e prospettive per il Duemila. Roma: Fratelli Palombi editori.

Deeming, D. C. 2018. Use of woody materials in nests reflects body mass in passerines. Bird Study 65: 417-421.

Di Santo, M., M. A. Bologna, and C. Battisti. 2017. Nest tree selection in a crowded introduced population of Monk parakeet (Myiopsitta monachus) in Rome (central Italy): evidence for selectivity. Zoology and Ecology 27 (3-4): 196-201.

Dytham, C. 2011. Choosing and using statistics: a biologist's guide. New York: John Wiley and Sons.

Eberhard, J. R. 1996. Nest adoption by Monk parakeets. The Wilson Bulletin 108: 374-377.

Eberhard, J. R. 1998. Breeding biology of the Monk parakeet. The Wilson Bulletin 110: 463-473.

Harrison, C. J. O. 1973. Nest-building behaviour of quaker parrots Myiopsitta monachus. Ibis 115: 124-128.

Hyman, J., and S. Pruett-Jones. 1995. Natural history of the Monk parakeet in Hide Park, Chicago. Wilson Bulletin 107: 510-517.

Mainwaring, M. C., I. R. Hartley, M. M. Lambrechts, and D. C. Deeming. 2014. The design and function of birds' nests. Ecology and Evolution 4: 3909-3928.
McDonald, B. A., W. S. Brooks, and B. E. P. B. O'Connell. 1995. Possible insect repellent function of green leaves placed on nests by hawks. Passenger Pigeon 57: $37-40$.

Navarro, J. L., M. B. Martella, and E. H. Bucher. 1992. Breeding season and productivity of Monk parakeets in Cordoba, Argentina. Wilson Bulletin 104: 413-424.

Pranty, B. 2009. Nesting substrates of Monk parakeets (Myiopsitta monachus) in Florida. Florida Field Naturalist 37: 51-57.

Reed, J. E., R. A. McCleery, N. J. Silvy, F. E. Smeins, and D. J. Brightsmith. 2014. Monk parakeet nest-site selection of electric utility structures in Texas. Landscape and Urban Planning 129: 65-72.

Romero, I. P., M. Codesido, and D. N. Bilenca. 2015. Nest building by Monk parakeets Myiopsitta monachus in urban parks in Buenos Aires, Argentina: Are tree species used randomly? Ardeola 62: 323-333.

Ruiz-Castellano, C., G. Tomas, M. Ruiz-Rodriguez, D. Martin-Galvez, and J. J. Soler. 2016. Nest material shapes eggs bacterial environment. PLoS One 11: e0148894.

Sonnenberg, B. R., C. L. Branch, L. M. Benedict, A. M. Pitera, and V. V. Pravosudov. 2020. Nest construction, ambient temperature and reproductive success in a cavity-nesting bird. Animal Behaviour 165: 43-58.

Viana, I. R., D. Strubbe, and J. J. Zocche. 2016. Monk parakeet invasion success: a role for nest thermoregulation and bactericidal potential of plant nest material? Biological Invasions 18: 1305-1315.

Volpe, N. L., and R. M. Aramburú. 2011. Preferencias de nidificación de la cotorra argentina (Myiopsitta monachus) en un área urbana de Argentina. Ornitologia Neotropical 22: 111-119. 